\title{
ALGUNAS MUESTRAS DE LITERATURA AUTOBIOGRÁFICA EN LA PRENSA ESPAÑOLA
} (1975-2010)

\section{SOME SAMPLES OF AUTOBIOGRAPHICAL LITERATURE IN THE SPANISH PRESS (1975-2010)}

\author{
Pablo NÚÑEZ DÍAZ \\ Centro Asociado a la UNED de Asturias \\ ndpablo@gijon.uned.es
}

Resumen: Autobiografías, memorias y escritos diarísticos han experimentado un auge indudable en España desde 1975. Al igual que sucedió con otros géneros en diferentes épocas de nuestra literatura, tanto periódicos como revistas han sido medios fundamentales para su publicación. En este trabajo se lleva a cabo una aproximación a la presencia de dichos textos en la prensa española, desde la fecha mencionada hasta 2010.

Abstract: Autobiographies, memoirs and diaries have undoubtedly undergone an increase in Spain since 1975. As it happened with other genres, at different periods of the history of our literature, authobiografical literature has been very present in periodical publications. In this work there is an effort to approach the importance of these texts in the Spanish press, since the already mentioned date, until 2010. 
Palabras clave: Literatura. Periodismo. España (desde 1975). Autobiografías. Memorias. Diarios.

Key words: Literatura. Journalism. Spain (since 1975). Authobiographies. Memoirs. Diaries.

La importancia de autobiografías, memorias y diarios como textos dignos de estudio filológico quedó de manifiesto en la segunda mitad del siglo XX, cuando se llevó a cabo, por primera vez, un análisis riguroso de la literatura del yo ${ }^{1}$. Asimismo, hace más de dos décadas se derribó el mito de que dicha literatura fuera escasa en España, frente a la abundancia de la misma en Estados Unidos, Francia o el Reino Unido. Tal y como pusieron de relieve Anna Caballé (1991 y 1995) y James Fernández (1991), entre otros autores, nuestro país contaba ya con su propia tradición de obras autobiográficas, que además experimentaron un auge indudable a partir de 1975 (a este respecto, vid. José Romera Castillo, 1991 y 1993; Ángel Basanta y Ángel G. Loureiro, 1996).

El objetivo de este breve (y selecto) estudio es llevar a cabo un acercamiento a la presencia que han tenido en la prensa las autobiografías, las memorias y la producción diarística de escritores españoles, desde la fecha mencionada hasta 2010. La investigación ha permitido trazar un panorama de dicho periodo, centrado exclusivamente en los autores contemporáneos al mismo, y sobre todo en aquellos que han cultivado la literatura autobiográfica de forma significativa. No se trata, por lo tanto, de ofrecer un recuento exhaustivo de todo lo publicado. De igual forma, se dejarán al margen otras modalidades de este tipo de escritura - por ejemplo, los epistolarios-, así como los textos de ficción y los poemas que puedan tener mayor o menor contenido autobiográfico.

El año en que se inicia el intervalo de tiempo en cuestión, 1975, ha sido elegido por una razón evidente: a partir de la muerte de Francisco Franco, y con la posterior llegada de la democracia, la libertad con la que comienza a escribirse en España marcó un antes y un después en la prensa del país, no solo en lo que se refiere a la información y la opinión, sino también a los

1 El principal ejemplo de ello lo constituyen las obras de Philippe Lejeune, entre las que se encuentran L'autobiographie en France (1971), Le pacte autobiographique (1975) y Moi aussi (1986). Una selección de sus aportaciones críticas se recogió en español bajo el título El pacto autobiográfico y otros estudios (1994). En nuestro país destacan los trabajos publicados en las últimas décadas por José Romera Castillo y Anna Caballé, directores del Centro de Investigación de Semiótica Literaria, Teatral y Nuevas Tecnologías (SELITEN@T-UNED) y de la Unidad de Estudios Biográficos (Universidad de Barcelona), respectivamente. 
textos que nos ocupan, cuyos autores tuvieron al fin la posibilidad de escribir sin censura. Esto resulta fundamental a la hora de compartir con los lectores experiencias vitales - tanto sociales como íntimas-y de mostrarles una visión personal del mundo que nos rodea.

\section{MEMORIAS Y OTROS ESCRITOS AUTOBIOGRÁFICOS ${ }^{2}$}

En las páginas del diario El País aparecieron varias entregas de la segunda parte de una de las obras autobiográficas más relevantes de la segunda mitad del siglo XX en español: La arboleda perdida, de Rafael Alberti (Alberti, 1987), cuyo primer tomo, publicado en 1959, y dividido en dos libros, recoge las memorias del poeta hasta la llegada de la II República Española. Las mencionadas entregas publicadas en El País vieron la luz entre noviembre de 1984 y diciembre de 1987. En la primera de ellas, el diario presenta así los escritos del autor:

Rafael Alberti amplía sus memorias tituladas La arboleda perdida, con los artículos que EL PAÍS ofrecerá periódicamente a partir de hoy, y que han comenzado a publicarse en el diario italiano Il Corriere della Sera (El País, 11 de noviembre de 1984: 13).

Precisamente fue el entonces director del Corriere della Sera, Piero Ostellino, quien le convenció para continuar La arboleda perdida, después de que el poeta recibiera un buen número de peticiones que no llegó a atender (Alberti, 1987: 7): «Tengo ahora más de 81 años. Demasiados. Demasiadas cosas que contar. Demasiado siglo catastrófico para tener que hablar de mí sin desenredarme de él», pensaba (ibid.). Así pues, el hecho de que Alberti llegara a escribir el segundo tomo de sus memorias se debió al encargo de una publicación periodística. A su director le dirigió entonces el siguiente comentario en el fragmento que introduce la primera entrega — «De Buenos Aires al Trastevere»-, que posteriormente sirvió de prólogo al volumen en cuestión: «y ahora, sin orden cronológico, irá usted recibiendo, espero que con puntualidad, retazos, según el viento me los vaya trayendo, de mi Arboleda perdida» (ibid.).

2 Sobre la literatura autobiográfica publicada a lo largo de dichos años, además de los mencionados trabajos de Romera Castillo, Á. Basanta y Á. G. Loureiro, vid. Fernández Prieto y Hermosilla Álvarez (2004), Romera Castillo (2006a y 2010a), VV. AA. (2000 y 2002), etc. 
En efecto, estas entregas no se publicaron en el orden cronológico que siguen en el libro: por ejemplo, la mencionada «De Buenos Aires al Trastevere» (El País, 11 de noviembre de 1984: 13) relata su marcha de Argentina a Roma en el año 1963, y pasó a ser el capítulo XXVIII del Libro III (Alberti: 1987, 163-167), en el que se incluyen además dos sonetos que no aparecieron en la versión periodística: «Lo que dejé por ti», de Roma peligro para caminantes (1968), y el soneto blanco que Jorge Guillén escribió a propósito de este libro de poemas de Alberti, y que tituló de igual forma.

En la siguiente entrega, «De la agonía de Las meninas a su resurrección» (El País, 25 de noviembre de 1984: 15), que constituye el capítulo trece de dicho Libro III (pp. 76-80), Alberti cuenta la importancia que el Museo del Prado tuvo para él desde que se instaló con su familia en Madrid en 1917, y cómo durante la Guerra Civil colaboró junto con su esposa, María Teresa León, en la evacuación de cuadros como Carlos V en la batalla de Mühlberg de Tiziano y Las Meninas de Velázquez, que fueron trasladados a Valencia y posteriormente a Ginebra, para su salvaguarda. Como en otras de las entregas, el salto temporal está motivado por la actualidad periodística3: en aquellos días de 1984, se exhibía en el Museo del Prado la obra de Velázquez recién restaurada:

aún más esplendorosa y vital que cuando yo la vi, por vez primera, aquella mañana del mes de mayo de 1917, hace ahora mucho más de cuarenta años, recién llegado del Puerto de Santa María, mi ciudad natal, en la maravillosa y mítica bahía gaditana (Alberti, 1987: 80).

En el diario El País, las entregas de 1984 aparecieron en la Tribuna de las páginas de «Opinión», mientras que a partir de 1985 pasaron al suplemento «Domingo». El propio autor explica que sus recuerdos sobre Pablo Neruda los había escrito un año antes, pensando en una futura continuación de La arboleda perdida (Alberti, 1987: 137), aunque no se hubiera decidido todavía a iniciar el proyecto. Por lo tanto, dicho texto es previo al encargo periodístico.

También ha de señalarse el caso de «El cometa Halley» (El País, 20 de enero de 1985: 15), que se incluyó en dichas memorias con posterioridad a

3 Otro ejemplo de ello es el capítulo dedicado a su larga amistad con Pablo Picasso, y al recuerdo de su muerte en 1973, pues está escrito a raíz de que se expusieran en Madrid fotografías del artista malagueño a finales de 1984 (Alberti, 1987: 192-196; publicado en El País bajo el título «Los ojos de Picasso», 9 de diciembre de 1984: 13). 
la muerte del poeta, en la edición aparecida dentro de sus obras completas (Alberti, 2009). Lo mismo ocurrió con varios artículos publicados en El País al margen de su Arboleda: por ejemplo, «No más casas» (El País, 4 de octubre de 1987: 15) y «Balada de cumpleaños» (ibid., 16 de diciembre de 1987: 36).

Francisco Ayala, autor de una sólida obra narrativa y ensayística, publicó los libros autobiográficos Recuerdos y olvidos (1988), El tiempo y yo, o El mundo a la espalda (1992) y De mis pasos en la tierra (1996), que conforman hoy el segundo volumen de sus obras completas (Ayala, 2010). En $A B C$ vio la luz un extracto de la edición ampliada de Recuerdos y olvidos (Ayala, 2006) — en la que se añadía una cuarta parte a las tres ya publicadas: «De vuelta a casa», que abarca desde 1980 hasta dicho año-. El texto de $A B C$ llevó por título «En la arena, en el agua, en el viento...» (19 de febrero de 2006: 66-67).

Tras su regreso a España, en la década de 1970, Rosa Chacel colaboró en diversas publicaciones periódicas, como ya hiciera en los años veinte y treinta en nuestro país, y también en sus años de exilio, especialmente en Argentina. Lo autobiográfico está presente en algunas de sus colaboraciones del período al que hemos de limitarnos, como se muestra en los dos volúmenes de artículos de su Obra completa (Chacel, 1993a y 1993b). Un ejemplo de ello es el escrito «1933» (suplemento «Culturas» de Diario 16, 14 de mayo de 1988: p. v), en el que recuerda su estancia en Berlín el año en que Hitler llegó al poder. Asimismo, bajo el título «Autobiografía intelectual» (Anthropos, núm. 85, junio de 1988: 16-27), la autora recupera fragmentos de su libro de memorias Desde el amanecer (1972), añadiendo nuevos recuerdos y reflexiones.

Lo autobiográfico aparece en la obra periodística de Gonzalo Torrente Ballester, recogida en sus libros Nuevos Cuadernos de La Romana (Torrente Ballester, 1976) ${ }^{4}$, Cotufas en el golfo (ibid., 1987) y Torre del aire (ibid., 1992). No se trata solo de sus anotaciones diarísticas publicadas en Informaciones, bajo los títulos «Cuadernos de La Romana» y «Torre del aire» —en las que nos detendremos en el apartado correspondiente a los diarios-, sino también de algunas de las colaboraciones que firmó semanalmente en $A B C$, entre 1981 y 1986, en la sección que daría título al tercero de los volúmenes mencionados. Los artículos de Cotufas en el golfo «se inclinan hacia el en-

\footnotetext{
4 No haré referencia a los Cuadernos de La Romana (1975), cuyas colaboraciones periodísticas son previas al periodo estudiado.
} 
sayismo» (Molina, 1992: XIII), si bien en algunos de ellos no deja de estar presente el carácter diarístico de sus escritos de Informaciones, o el más propiamente autobiográfico. Ejemplos de esto último son sus recuerdos de un viaje a Weimar (Torrente Ballester, 1987: 75-78), del curso que pasó en Oviedo como estudiante universitario (ibid.: 149-152) o de su etapa de entreguerras en Galicia y Madrid (ibid.: 256-260).

Camilo José Cela publicó en 1959 La rosa, como primer libro de su proyecto de memorias, nacido con el título general La cucaña. Esta entrega inicial, que abarca desde su niñez hasta su primera juventud, había aparecido ya en las páginas del Correo Literario en 1950 y del semanario Destino en 1953 y 1958 (Cela, 2001: 23). Once de las entregas de Destino no fueron incorporadas al libro hasta 2001, después de que se publicaran en el suplemento «Ababol» del diario La Verdad de Murcia, del 5 de septiembre al 14 de noviembre de 1997 (ibid.). Cela reanudó el proyecto de sus memorias completas con una obra que trascurre sobre todo en Madrid, en época de «pubertad siniestra»y de «primera juventud», en palabras del novelista, y que llevó por título Memorias, entendimientos y voluntades (Cela, 1993). El comienzo de este libro constituye una declaración de intenciones por parte del autor, que pone de relieve su forma de abordar lo autobiográfico:

Las potencias del alma son tres, memoria, entendimiento y voluntad, y con las memorias, los entendimientos y las voluntades de todos se convive o se malvive, se ama o se odia, se juega o se pelea y, en definitiva, se escribe la historia, eso que para Carlyle no es más cosa que la destilación del rumor. Esto que ahora comienzo no sé lo que va a ser, aunque procuraré que no sea un ensayo sino una narración, siempre verdadera aunque a parte de la verdad la deje huir para que nadie pueda atrapar a nadie con su hedor (Cela, 1993: 7).

Más adelante señala que estas memorias no aspiran a ser «una interpretación de la historia, cotidiana y a ras de tierra, una crónica contada paso a paso y según fueron viniendo las cosas, las buenas y las malas, que de todo hubo en la viña del Señor» (ibid.: 7), y que en ningún caso pedirá disculpas, «porque no me avergüienzo ni me arrepiento de nada de lo que haya podido hacer y porque tengo la fundada evidencia de que no lleva a ningún lado el implorar caridad» (ibid.: 7). Al comienzo del segundo capítulo, vuelve a referirse al orden cronológico de su relato, que es en realidad «muy relativo», según señala, «porque tampoco quiero atarme demasiado ni cerrar puertas a la enmienda o a la necesidad» (ibid.: 12). Memorias, entendimien- 
tos y voluntades se publicó por entregas en Gente, revista dominical de Diario 16, desde el 15 de diciembre de 1991.

Miguel Delibes incluyó artículos autobiográficos en sus libros El otro fútbol (1982), La censura de prensa en los años 40 y otros ensayos (1985), Pegar la hebra (1990) y He dicho (1996). Una relación de dichos artículos, con los datos de publicación de aquellos que aparecieron en El Norte de Castilla y de varios de ellos que vieron la luz en El Semanal —en el primero, al menos doce escritos entre 1982 y 1995, y en el segundo cinco entre 1991 y 1994, uno de los cuales ya había aparecido con anterioridad en el mencionado El Norte de Castilla -, se encuentra en el séptimo volumen de las obras completas del escritor vallisoletano, cuya edición estuvo a cargo de Ramón García Domínguez (Delibes, 2007: 1085-1089)5.

El novelista y político Jorge Semprún recogió en varios libros autobiográficos sus vivencias de algunos hechos de verdadero interés histórico: su experiencia como prisionero en los campos de concentración de Weimar y Buchenwald, su militancia en el Partido Comunista de España durante el franquismo y su expulsión del mismo, su vida en el exilio y su activismo antifranquista... Así nacieron los libros El largo viaje (1964), Autobiografía de Federico Sánchez (1977), Federico Sánchez se despide de ustedes (1993), La escritura o la vida (1994) y Adiós, luz de veranos (1998). Cuando apareció la última obra mencionada (Semprún, 1998), escrita en francés y traducida al español por Javier Albiñana, El País recogió varios extractos con idéntico título (5 de abril de 1998, pp. 18 y 19 del suplemento «Domingo» 651).

En sus artículos del diario El País, además de abordar cuestiones políticas o literarias, Juan Benet se detuvo en más de una ocasión a recordar determinadas vivencias, por ejemplo de su etapa en el bachillerato ( Sobre la cartografía elemental», El País, 12 de agosto de 1982: 7) y del servicio militar («Un vuelo», El País, 4 de octubre de 1982: 11), o de sus reuniones clandestinas con el pequeño grupo denominado Unión Social Democrática Española, que lideraba Dionisio Ridruejo («El grupo de San Lucas», El País, 9 de junio de 1985: 35).

Como es bien sabido, Francisco Umbral publicó diversas obras de carácter autobiográfico o memorialístico, como La noche que llegué al Café Gijón (1977), Trilogía de Madrid (1984), Memorias de un niño de dere-

5 Cf. los estudios de José Romera Castillo (2006d y 2010b). 
chas (1986), Un ser de lejanías (2003), etc. «En realidad, toda mi obra es memorialística», afirma el escritor en el prólogo a uno de sus últimos libros (Umbral, 2005: 7), y si esto es aplicable a su narrativa, no con menos razón puede afirmarse de sus artículos periodísticos. Tanto en sus columnas de El País — publicadas entre 1976 y 1983, primero bajo el título «Diario de un snob»y, posteriormente, «Spleen de Madrid»-, como en las de La Vanguardia en la década de 1970, las de Diario 16 — de 1988 y 1989, tituladas «Diario con guantes» y «Los iluminados»- y El Mundo — publicadas desde 1989 hasta su muerte, con el título «Mis placeres y mis días»-, aparecen referencias vitales entremezcladas con el comentario sobre la actualidad política o cultural. Sus columnas del periodo que nos ocupa se han recogido en diversos volúmenes, por ejemplo en Iba yo a comprar el pan (Umbral, 1976), Diario de un snob / 2 (Umbral, 1978); Diario de un escritor burgués (Umbral, 1979) o, entre los posteriores, Mis placeres y mis días (Umbral, 1994).

Por su parte, Soledad Puértolas (Zaragoza, 1947) y Javier Marías (Madrid, 1951) han publicado sendos volúmenes con sus colaboraciones periodísticas más autobiográficas. Así, bajo el título Recuerdos de otra persona (Puértolas, 1996), la escritora recogió por ejemplo artículos sobre su infancia y sobre distintos lugares en los que residió o que visitó, y que tuvieron un significado especial para ella (Zaragoza, Pamplona, Madrid, Noruega, California, Berlín). Más reciente es el libro de Marías Aquella mitad de mi tiempo (Marías, 2008), recopilación de ochenta y dos piezas, en su mayor parte artículos aparecidos entre 1989 y 2008 en El Semanal, El País y El País Semanal. En dicha obra los textos se agrupan de acuerdo con los temas abordados, entre los que se encuentran su infancia, su juventud, sus padres — Julián Marías y Dolores Franco-, o los literatos a los que trató de joven (en especial a Juan Benet).

En la obra periodística de Antonio Muñoz Molina (Úbeda, Jaén, 1956) aparecen en ocasiones referencias autobiográficas, fundamentalmente cuando ciertas situaciones de la actualidad guardan relación con otras ya vividas. Así ocurre, por ejemplo, en el artículo «Soldados» —El País, 23 de abril de 1990: 13, recogido cinco años más tarde en Las apariencias (Muñoz Molina, 1995: 91-95)—. En él recuerda su experiencia en el servicio militar, a raíz de que esos días se juzgara a un cabo por la muerte de un recluta. Otras muestras de ello son varios artículos publicados en la edición andaluza de El País en 1995, incluidos al año siguiente en el libro La huerta del Edén (Muñoz Molina, 1996), en los que está muy presente su infancia en Granada: v. g. «Luto por los árboles» (ibid.: 19-22), «Elogio laico de la bi- 
blioteca» (ibid.: 39-42), «Congojas de verano» (ibid.: 51-54) e «Invierno y aceituna» (ibid.: 107-110).

Me referiré a continuación al ámbito poético. Una selección de la obra periodística de Ángel González, titulada 50 años de periodismo a ratos y otras prosas (González, 1998), incluye diversos textos de carácter autobiográfico, como los artículos que publicó en La Voz de Asturias, en 1984, con sus recuerdos de un viaje de ese mismo año a Utah, en cuya universidad había sido profesor visitante once años atrás (ibid., 97-110), o los que vieron la luz en El País en 1988, sobre sus vivencias en Londres (ibid., 133165), entre otros. Pero mayor importancia autobiográfica tienen dos escritos que no forman parte de dicha obra: «Jaime Gil de Biedma: breve evocación de una larga amistad» (Revista de Occidente 110-111, julio-agosto de 1990: 17-20) y, sobre todo, «Para que yo me llame Ángel González» (Anthropos 109, 1990: 19-29), en el que el poeta asturiano hace memoria de algunos de los principales acontecimientos de su vida, relacionándolos con su trayectoria como creador: la influencia de su madre y sus hermanos, la Guerra Civil, sus estudios y sus diferentes trabajos, su amistad con el «grupo de Barcelona», su compromiso político... Por ejemplo, escribe lo siguiente acerca de la poesía social:

La poesía social fue inevitable en un momento dado y, en mí por lo menos, nunca fue un tema impostado, sino que nació de un sentimiento propio, era producto de vivencias y de creencias que eran mías. La hubiera escrito en cualquier caso, aun sin tener en cuenta lo que decía Gabriel Celaya cuando hablaba de transformar el mundo. Nunca creí, desde luego, que esa poesía pudiese transformar el mundo, pero sí pienso que no fue del todo inútil (González, 1990: 26).

Juan Luis Panero (Madrid, 1942), en cuya obra poética abundan las referencias autobiográficas ${ }^{6}$, recogió en Los mitos y las máscaras (Panero, 1994) una selección de sus artículos de ABC, El País, La Vanguardia y Diario 16. Se trata de los textos que estaban «más cerca de mi poesía y de mi mundo personal» (ibid., 1994: 11), en palabras del autor de Galería de fantasmas, por lo que no es de extrañar que en ellos evoque sus encuentros con Jorge Luis Borges, Rosario Castellanos, Octavio Paz, Joan Vinyoli, etc. y

6 También ha publicado un libro autobiográfico en prosa: Sin rumbo cierto. Memorias conversadas con Fernando Valls (2000). 
que estén presentes su recuerdo infantil de T. S. Eliot o la importancia de Luis Cernuda como su poeta predilecto.

El libro de memorias de Miguel d'Ors (Santiago de Compostela, 1946) consta de alrededor de ochocientas páginas, en su mayor parte inéditas por voluntad del poeta y ensayista, que no ha decidido todavía publicarlo ${ }^{7}$. Sin embargo, de dicha obra han visto la luz veinticuatro capítulos, desde 1983 hasta 2006, en las siguientes publicaciones: Clarín, Farsalia, Ideal, el suplemento «La Mirada» de El Correo de Andalucía, Los Cuadernos del Sornabique, Los Papeles Mojados de Río Seco, Luzdegás, Númenor, Pretexto, Reloj de Arena, Renacimiento y Turia. En el título de la mayor parte de dichas entregas, el autor incluyó entre paréntesis la mención «Apunte para unas memorias», bien ilustrativo del proyecto en el que los textos se enmarcan. Un ejemplo es el capítulo que publicó, en 1995, bajo el título «De la vida del campo (Apunte para unas memorias)» (Reloj de Arena 13, diciembre de 1995: 23-25), en el que recuerda su infancia en las localidades pontevedresas de La Estrada y Paraños.

Luis Alberto de Cuenca (Madrid, 1950) incluyó secciones autobiográficas en sus recopilaciones de artículos tituladas Etcétera (Cuenca, 1993) y Señales de humo (ibid., 1999). También aparecen un buen número de referencias autobiográficas en las reseñas que ha publicado en la prensa, sobre todo en $A B C$, y que se recogen parcialmente en Álbum de lecturas (Cuenca, 1995), Libros contra el aburrimiento (Cuenca, 2011a) y Nombres propios (Cuenca, 2011b). El poeta, ensayista y traductor madrileño no ha publicado hasta la fecha ningún volumen de memorias ni de diarios, al considerar que «artículos y reseñas periodísticos cubren ese flanco de mi creatividad ${ }^{8}$.

Luis García Montero (Granada, 1958) narra sus recuerdos de infancia en dieciocho entregas publicadas en el suplemento «Artes y Letras» del periódico Ideal de Granada, entre el 10 de noviembre de 1989 y el 22 de junio de 1990. A lo largo de dichos escritos, agrupados en el volumen Luna en el sur (García Montero, 1992), la ciudad natal del poeta tiene un protagonismo indudable:

Aunque me esfuerce por cerrar los ojos siempre veré la luz acristalada de un otoño infinito, que se desnuda en silencio para rejuvenecer, sin aspavientos, melancólicamente, como los otoños hendidos de esta ciudad, Granada, luna

7 Correspondencia con el autor, de 3 de diciembre de 2012.

8 Correspondencia con el autor, de 22 de febrero de 2013. 
del sur, deseo tripulado y lleno de interrogaciones, paisaje del niño que se mira en un estanque (García Montero, 1992: 72) .

El poeta también es autor del libro autobiográfico La casa del jacobino (García Montero, 2003), que reúne tanto escritos hasta entonces inéditos como otros aparecidos previamente en la prensa.

Capítulo aparte merecen los textos memorialísticos publicados por $\mathrm{El}$ País en el verano de 2006, en una sección titulada «Historias de familia», en la que colaboraron alrededor de treinta escritores. Como es obvio, resulta imposible detenernos aquí en todos los textos de dicha sección, por lo que solo mencionaré algunos ejemplos: José Manuel Caballero Bonald (Jerez de la Frontera, 1926) escribe sobre «los acostados», «un sector de los Bonald que habían optado un día por la cama, nunca después de los cuarenta o cuarenta y cinco años, como más idóneo lugar de residencia» («El tiempo no tiene paredes», 20 de agosto: 50); Juan Marsé (Barcelona, 1933) relató con humor cómo tuvo conocimiento de su condición de niño adoptado («De cuando yo tenía cuatro padres y ocho abuelos», 1 de agosto: 48 y 49); Luis Mateo Díez (Villablino, León, 1942) narra desapariciones puntuales y fortuitas del propio autor y de sus hermanos, en el nevado paisaje leonés de su infancia («Náufragos en la nieve», 19 de agosto: 45); Ana María Moix (Barcelona, 1947) revive una historia familiar relacionada con el día de Reyes («Jeromín en el Raval», 21 de agosto: 39); y Carme Riera (Palma de Mallorca, 1948), en su escrito «Con el alma violeta» ${ }^{10}(28$ de agosto: 47) rememora su imagen de niña, su temprano inicio en la escritura y algunas de las historias que le narraba su abuela paterna, que le encaminaron hacia la literatura ${ }^{11}$.

También han de mencionarse, por ejemplo, los casos de Juan Gil-Albert, de quien se publicó el texto "Autobiografía», póstumamente, en el Boletín de la Unidad de Estudios Biográficos ${ }^{12}$ (núm. 1, 1996: 85-90); Antonio Gala (Brazatortas, Ciudad Real, 1930) y su obra Dedicado a Tobías (Gala, 1988),

9 El libro se completa, acertadamente, con tres poemas autobiográficos: «Sonata triste para la luna de Granada», «Casa en ruinas» y «Espejo, dime».

10 Publicado con el erróneo título «Con el alma violenta».

11 También participaron Bernardo Atxaga, Nuria Barrios, Luisa Castro, Juan Luis Cebrián, Javier Cercas, Inma Chacón, Susana Fortes, Almudena Grandes, Luis Landero, Elvira Lindo, Julio Llamazares, Berta Marsé, Gustavo Martín Garzo, César Antonio Molina, Rosa Montero, Antonio Muñoz Molina, Manuel Rivas, Clara Sánchez, Marta Sanz, Suso de Toro e Irene Zoe Alameda, así como escritores de otras nacionalidades —en este artículo he de limitarme a los españoles - y varios cineastas.

12 En esta revista, conocida desde 2003 como Memoria, se han recogido importantes aportaciones sobre el estudio de la literatura autobiográfica. 
«una serie de reflexiones, recuerdos y fragmentos autobiográficos aparecidos en El País Semanal» (Romera Castillo, 1996: 44); Antonio Colinas (La Bañeza, León, 1946), que publicó en El País un texto autobiográfico titulado «El crujido de la luz» ${ }^{13}$ (10 de enero de 1987: 9); Jon Juaristi (Bilbao, 1951), que hizo lo propio en $A B C$ (15 de enero de 2006: 78 y 79) con un adelanto de su libro de memorias Cambio de destino (Juaristi, 2006); Luis Antonio de Villena (Madrid, 1951) y su precoz autobiografía Ante el espejo (Villena, 1982), de la que apareció un extracto en Cuadernos del Norte (núm. 14, julio-agosto de 1982: 52-58), bajo el título «El amor celeste» ${ }^{14}$; Laura Freixas (Barcelona, 1958), quien publicó un capítulo de su autobiografía en Letras Libres (núm. 22, julio 2003, 50-54), titulado «Cumplir cuarenta»; y Blanca Andreu (La Coruña, 1959), que escribió a partir de recuerdos de su infancia el texto en prosa «Verde vino del viento de septiembre» (Cuadernos del Norte 16, noviembre-diciembre de 1982: 70 y 71).

\section{DIARIOS ${ }^{15}$}

No son pocos los escritores españoles que, como ya lo hiciera André Gide, publicaron en vida sus diarios, o parte de ellos, a lo largo del siglo XX - Rosa Chacel, César González-Ruano, Dionisio Ridruejo, Miguel Delibes, Carmen Laforet y Jaime Gil de Biedma, entre otros_ o todavía lo hacen en nuestros días — por ejemplo, Iñaki Uriarte, José Luis García Martín, Miguel Sánchez-Ostiz y Andrés Trapiello-. Como ya se ha indicado, en este artículo he de centrarme en autores que firmaron dichos textos diarísticos en la prensa de nuestro país en las últimas décadas.

Desde octubre de 1973 hasta agosto de 1975, Gonzalo Torrente Ballester publicó, en el periódico Informaciones —en concreto, en el suplemento semanal «Informaciones de las Artes y las Letras»-, sus «Cuadernos de La Romana», que pueden considerarse «el diario de trabajo de un escritor» (Molina, 1992: IV). Torrente Ballester aceptó la propuesta de Informaciones de escribir un diario, en parte, por la seguridad que le confería el hecho de

13 Su título recuerda al último verso del poema de Antonio Colinas «Paraíso en la nieve», perteneciente al libro Los silencios de fuego (1992), y coincide con el de su obra memorialística publicada en 1999.

14 Otro interesante escrito autobiográfico del autor es «La tarde en Velintonia», sobre su amistad con Vicente Aleixandre (Ínsula 458-459, enero-febrero de 1985: 6).

15 Sobre la escritura diarística en el periodo que nos ocupa, vid. Alberca (2000), Caballé (1996), Freixas (1996), Gracia (1997), Gracia y Mainer (2000) y Romera Castillo (2000, 2004, 2006b y 2006c), entre otros autores. 
que Carmen Laforet y Miguel Delibes también hubieran publicado el suyo recientemente en Destino, aunque le surgieron dudas «por el hecho mismo de publicar algo que pertenece a la intimidad» (Torrente Ballester, 1976: 7):

Yo soy bastante tímido, razonablemente humilde y pudoroso en exceso, pero semejantes defectos he tenido que dominarlos, ya que desde muy pronto me vi obligado a vivir de la pluma. Y todo lo que llevo publicado en los periódicos, de una manera o de otra, pudiera reducirse a «diario» con solo poner fecha y cambiar título.

Al igual que los «Cuadernos de La Romana» tomaban el nombre de la casa en la que el autor residía durante los años de su redacción, ubicada en Nigrán (Pontevedra), su traslado a Salamanca en septiembre de 1975 conllevó también el cambio de dicho título por «Torre del aire», que es como se conoce al remate de un caserón medieval que podía ver desde su nueva residencia (Torrente Ballester, 1992: 1). El novelista mantuvo esta colaboración hasta el cierre de Informaciones, en diciembre de 1979. En «Torre del aire» aparecen, por ejemplo, sus comentarios sobre algunos de los volúmenes de su biblioteca, a raíz del traslado de esta a su nueva casa (ibid., 6-8); sus impresiones acerca de una conferencia de Dámaso Alonso sobre Antonio Machado y su encuentro con el primero al día siguiente de la misma (ibid., 9); la visita a Cantabria para participar como jurado de un premio literario, la elección del ganador y la secuela de dicho galardón (ibid., 21-25); un encuentro con Luis Rosales y Gerardo Diego (ibid., 34-35), etc.

Juan Goytisolo (Barcelona, 1931) —además de novelista, autor de los libros de memorias Coto vedado (1985) y En los reinos de Taifas (1986), reunidos en Memorias (2002) — publicó en El País un diario escrito durante ocho días en las calles de Sarajevo, adonde viajó para conocer de cerca y denunciar el genocidio de los musulmanes de Bosnia-Herzegovina. El Cuaderno de Sarajevo (Goytisolo, 1993) apareció por entregas desde el 23 de agosto de 1993. El día anterior, El País anunció que se publicaría simultáneamente en sus páginas y en las de «Aftonbladet de Estocolmo, La Repubblica de Roma, Le Monde de París, El Nacional de México, El Espectador de Bogotá y La Nación de Buenos Aires» (El País, 22 de agosto de 1993: 22).

Entre 2005 y 2008, el novelista Enrique Vila-Matas (Barcelona, 1948) escribió fragmentos de su cuaderno personal para la edición dominical de $E l$ País de Cataluña, que hoy se recogen en el libro Dietario voluble (VilaMatas, 2008). Según se indica en su contraportada, no solo está compuesto por los textos aparecidos en prensa, sino por otros «que no se movieron del 
cuaderno y que ahora dejan de ser inéditos, y también por notas que han sido escritas para completar esta edición».

En 2007, la revista Zut publica el «Cuaderno Moleskine» de Javier Marías (núm. 5, invierno de 2007: 78-92; recogido posteriormente en Marías, 2008: 29-35), diario escrito seis años antes para un proyecto en el que participaron alrededor de un centenar de autores, con fines solidarios. Se trata de veintiún breves anotaciones correspondientes a los meses de septiembre y octubre, que comienzan precisamente el día en que el novelista cumple cincuenta años (20 de septiembre). En dicho cuaderno, el autor de Tu rostro mañana recoge algunos recuerdos de su infancia y reflexiona sobre el paso del tiempo:

Estos cincuenta años están llenos de cosas semiolvidadas y olvidadas del todo, eso es seguro. De esfuerzos considerables cuyo sentido se desconoce ahora, de zozobras muy vivas de las que no queda rastro en la memoria, de angustias y de haber dado la mayor importancia, una importancia vital, a personas o hechos que hoy no cuentan, o aún es más, apenas si se recuerdan (ibid., 2008: 34) ${ }^{16}$.

Antonio Muñoz Molina firmó entregas semanales de su Diario del Nautilus (Muñoz Molina, 1989) en el Ideal de Granada, entre septiembre de 1983 y junio de 1984. A pesar de su título, no abundan en él las secuencias de la vida del novelista, que prefiere fijar su mirada en otros personajes y en cuestiones relacionadas con el acontecer diario, sin dejar apenas constancia de su propia intimidad. Incluso los fragmentos más personales respetan un límite marcado tal vez por la inteligencia pudorosa de su autor. Así, en el capítulo «Más allá de este muro» (Muñoz Molina, 1989: 107-110), en el que cuenta cómo vuelve a casa, a su despacho, una lluviosa tarde de marzo, recordando un soneto de Antonio Carvajal, pasa pronto a reflexionar sobre el cuarto centenario del nacimiento del granadino Pedro Soto de Rojas, quien se convierte entonces en el protagonista del escrito.

En el terreno poético, de Jaime Gil de Biedma aparecieron en El País, entre el 31 de diciembre de 1990 y el 5 de enero de 1991, cinco textos de su libro Retrato del artista en 1956 (Gil de Biedma, 1991), como anticipo

16 El otro texto diarístico de Javier Marías que vio la luz en prensa es el «Diario de Zürich», publicado en la revista suiza Die Weltwoche en 1997 y 1998, pero, a pesar de su interés literario, como no apareció en la prensa española sobrepasa los límites de este artículo (sobre el «Diario de Zürich», vid. Núñez Díaz, 2011: 125-127 y 342-344). 
de su publicación en la editorial Lumen, al cumplirse el primer aniversario de la muerte del poeta. Lumen ya había publicado la primera parte de dicha obra en 1974, bajo el título Diario del artista seriamente enfermo. En las entregas de El País conocemos detalles de su vida en Manila, ciudad en la cual, como es bien sabido, pasó varias temporadas por su trabajo como ejecutivo en la Compañía General de Tabacos de Filipinas, y sobre el viaje que realizó, como parte de su cometido en la empresa, a varias localidades de las islas Bisayas. Sus relaciones personales y sentimentales ocupan un lugar destacado en dichos textos: "Central Azucarera de Bais» (El País, 31 de diciembre de 1990: 20-21), «Iloilo, Panay» (ibid., 2 de enero de 1991: 25), «Cebú» (ibid., 3 de enero de 1991: 22), «En vuelo a Manila» (ibid., 4 de enero de 1991: 28) y «Manila» (ibid., 5 de enero: 20-21).

Clara Janés (Barcelona, 1940) prefiere no publicar sus diarios, «para mantener el misterio de la creación» (Goñi, 1993: 10). Sin embargo, hizo una excepción al dar a la imprenta algunas anotaciones correspondientes a septiembre y octubre de 1982, tituladas «Cuaderno de Carmen», que vieron la luz en la revista Un Ángel Más en 1989 (núm. 7-8: 171-178), junto a colaboraciones igualmente interesantes de Ángel Crespo ( Días sueltos de un diario»: 145-161), José Ángel Valente («Notas de un simulador»: 319-322), María Zambrano («El diario de otro»: 9-10), etc.

Entre los escritos de Víctor Botas, que permanecen inéditos, se encuentran su diario y unas memorias, que se conservan en la Biblioteca de Asturias «Ramón Pérez de Ayala». Aproximadamente una cuarta parte del diario se publicó en la revista Clarín en 2004, al cumplirse diez años de la muerte del poeta. Se trata de una selección de pasajes realizada por José Luis García Martín y titulada «Diario inédito (1981-1987)» (Clarín 53, septiembreoctubre 2004: 48-55).

Hilario Barrero (Toledo, 1946), poeta y traductor, ha publicado hasta la fecha seis libros de diarios —Las estaciones del día (2003), De amores y temores (2005), Días de Brooklyn (2007), Dirección Brooklyn (2009), Brooklyn en blanco y negro (2011) y Nueva York a diario (2013)—. Del primero de ellos (Barrero, 2003), ofreció un adelanto el periódico asturiano El Summum, bajo el título «Días de invierno en Brooklyn» (núm. 3, enero de 2002: 26).

El poeta Luis Javier Moreno (Segovia, 1946), autor de los diarios La puntada y el nudo (1993), En el cuartel de invierno (1997), Cuaderno de paso (2000) y Horas marinas (2005), publicó también textos diarísticos en 
un cuadernillo titulado Fragmentos de diario, que se entregó junto con la revista vallisoletana P.O.E.M.A.S. en el año 2000. Asimismo, en la revista Clarín, en el año 2006, firmó anotaciones inéditas que abarcan del 11 al 26 de marzo de 1989, bajo el título «De Segovia a Estocolmo. Nuevas páginas de mi diario íntimo» (Clarín 62, marzo-abril de 2006: 31-35).

Además de sus libros de poesía y de crítica literaria, dentro de la obra de José Luis García Martín (Aldeanueva del Camino, Cáceres, 1950) destaca su diario, del que se han publicado ya doce volúmenes, el primero de ellos en 1989. Su diario reviste especial importancia para el tema que nos ocupa: desde septiembre de 2005 aparece por entregas en La Nueva España, con periodicidad semanal, y fruto de esta colaboración son los libros A decir verdad (García Martín, 2006), La vida misma (2007), Hotel Universo (2009) y Para entregar en mano (2011). García Martín, que vive en Asturias desde su niñez, donde ejerce la docencia universitaria y dirige la revista Clarín, explica que ya había conseguido dejar durante tres meses la «mala costumbre» de escribir su diario - el último le había costado, «como es habitual, algún pequeño disgusto y la pérdida de dos o tres amigos»-, cuando el entonces director de La Nueva España le ofreció publicarlo en las páginas del periódico asturiano. «De desnudarme en libro, que es como hacerlo en la intimidad, pasaría a desnudarme en las páginas de un periódico, o sea, en la plaza pública» (García Martín, 2006: 261), pensó el autor, sin que ello le impidiera aceptar finalmente la propuesta.

Precisamente la génesis del diario de García Martín ${ }^{17}$ se encuentra, casi tres décadas antes del mencionado acercamiento a la «plaza pública», en la revista de literatura Jugar con Fuego, que él mismo fundó y dirigió, y en la que aparecieron dos textos de carácter diarístico en 1977 y 1981, firmados bajo seudónimo: «Autorretrato de un desconocido» (3 de abril de 1977: 13-19; atribuido a Luigi Durutti) y «Papel mojado» (noviembre de 1981: 29-56; atribuido a Alfonso Sanz Echevarría). Años más tarde publica «Cinco días de marzo» en la revista Lunula (núm. 5, 1989: 54-64), texto que pasó a formar parte de la segunda edición de su libro Días de 1989. Asimismo, la mayor parte de los textos del volumen Dicho y hecho (García Martín, 1995) aparecieron semanalmente en La Voz de Asturias entre octubre de 1994 y junio de 1995, y tanto de este libro como de Todo

17 Las referencias de publicación que señalo en el presente párrafo — tras consultar los originales_- se recogen en Tramón (2005: 59-62). 
al día (García Martín, 1997) vieron la luz sendos anticipos en la revista Reloj de Arena ${ }^{18}$.

Varios fragmentos del diario de José Luna Borge (Sahagún de Campos, León, 1952), poeta y crítico literario, aparecieron en el suplemento de $E l$ Correo de Andalucía «La Mirada» a lo largo de los años 1995 y 1996, bajo el título «Veleta de la curiosidad», que hasta la fecha ha servido también como subtítulo de los volúmenes que recogen sus diarios, v. g., Pasos en la niebla (2001), Pasos en la nieve (2002), Pasos en el agua (2007), Pasos en la arena (2012).

Las anotaciones diarísticas del poeta y ensayista Andrés Sánchez Robayna (Santa Brígida, Las Palmas, 1952) conforman los libros La inminencia (Diarios, 1980-1995) (Sánchez Robayna, 1996) — «autorretrato estricto de la maduración de una poética precisa y meditada» (Gracia, 1997: 42) — y Días y mitos (Diarios, 1996-2000) (Sánchez Robayna, 2002), que ofrece de igual forma una crónica intelectual del acontecer diario, con anotaciones en las que inmortaliza diversos viajes o reflexiona sobre temas literarios, históricos, etcétera. Algunas entregas del diario de Sánchez Robayna han visto la luz en revistas como Letras Libres, Paradiso, Syntaxis, Turia y Un Ángel Más ${ }^{19}$.

Bajo el título Salón de pasos perdidos, Andrés Trapiello (Manzaneda de Torío, León, 1953) ha publicado ya dieciocho volúmenes de sus diarios, de los que José-Carlos Mainer escribió en 1997 que figuran «entre las obras definitivas de la literatura de los últimos veinticinco años españoles» (Gracia y Mainer, 2000: 460). Aparecidos en la editorial valenciana Pre-Textos, los volúmenes en cuestión son los siguientes: El gato encerrado (1990), Locuras sin fundamento (1993), El tejado de vidrio (1994), Las nubes por dentro (1995), Los caballeros del punto fijo (1996), Las cosas más extrañas (1997), Una caña que piensa (1998), Los hemisferios de Magdeburgo (1999), Do fuir (2000), Las inclemencias del tiempo (2001), El fanal hialino (2002), Siete moderno (2003), El jardín de la pólvora (2005), La

18 «Prosa de diario» (Reloj de Arena 8, marzo de 1994: 26-30) y «Días de 1996» (ibid. 15, septiembre de 1996: 21-24), respectivamente. Según comenta García Martín en una nota al segundo de dichos textos (p. 21), se trata de una selección de su diario que le solicitaron para un número de la Revista de Occidente dedicado al diario íntimo (núm. 182 y 183, julio-agosto de 1996), en el que nos detendremos más adelante. No llegó a incluirse en el mismo porque la directora de la revista le pidió que suprimiera un determinado fragmento y él se negó a publicar bajo censura.

19 Por ejemplo, en Turia 4-5 (1986), 49-50 y núm. 38 (1996), 70-81, y en el mencionado número de Un Ángel Más (7-8, 1989: 171-178). 
cosa en sí (2006), La manía (2007), Troppo vero (2009), Apenas sensitivo (2011) y Miseria y compañía (2013).

El primero de dichos libros (Trapiello, 1990) apareció por entregas en el suplemento «Citas» del Diario de Jerez, a partir del 21 de octubre de 1989. Del segundo de ellos, Locuras sin fundamento (ibid., 1993), vieron la luz sendos anticipos en las revistas Bitzoc (núm. 13, octubre de 1992: 27-46) y Turia (núm. 21-22, 1992: 82-86), mientras que del tomo Do fuir (Trapiello, 2000) se incluyeron algunas páginas en el número 182-183 de la Revista de Occidente (julio-agosto de 1996: 247-256). Andrés Trapiello también es autor de un interesante ensayo titulado El escritor de diarios (Trapiello, 1998), en el que lleva a cabo una reflexión teórica sobre el género (las posibles causas de su nacimiento, las relaciones entre vida y literatura, etc.) y ofrece su propio resumen de los últimos cien años de diarios españoles.

El poeta y novelista Carlos Marzal (Valencia, 1961) ha firmado textos diarísticos en la revista Sibila, bajo los títulos «Asuntos de conciencia (Fragmentos de un dietario)» (núm. 4, enero de 1996: 28-31) y «Dos apuntes del natural» (núm. 21, abril de 2006: 34-35), respectivamente, y uno más extenso y enjundioso en la revista Litoral, titulado «Los pobres desgraciados hijos de perra» (Diario. 1981-1995) (núm. 239: 138-155). Este último nace a partir de una cita de la obra de William Faulkner La mansión, que también dio nombre a un libro de relatos de Marzal, y se inicia con una «Advertencia (en el año 2005)» del autor de Metales pesados sobre su relación con la escritura diarística. En ella afirma que nunca disfrutó tanto «con el puro placer de la escritura» como en la época que tomó anotaciones de diario «con cierta regularidad» (Litoral 239: 140):

Por aquel entonces, soñaba con que terminaría haciendo — por la simple inercia acumulativa de la labor- un mamotreto de miles y miles de páginas, que daría cuenta de aquello a lo que los diarios aluden: parte de la figura que un escritor quiere trazar de sí mismo, una de las facetas del prisma.

Marzal llegó a reunir «unos centenares de páginas», pero la falta de tiempo y los diversos proyectos literarios que fue acometiendo le impidieron llevar a término su publicación. Esta selección aparecida en Litoral supone, de momento, la valiosa muestra de un proyecto que no llegó a ver la luz, si bien podría suponer el adelanto de un libro futuro. En las colaboraciones periodísticas de escritores abundan ambas posibilidades. 
Además de diversos poemarios, y un libro de ensayos líricos, Javier Almuzara (Oviedo, 1969) ha escrito dos obras que en cierto modo podemos considerar diarísticas, por lo que tienen de anotación y reflexión acerca de las vivencias cotidianas: Letra y música (Almuzara, 2001) y Títere con cabeza (Almuzara, 2005) ${ }^{20}$. De dichos libros aparecieron sendos anticipos en Reloj de Arena: «Quede constancia» (núm. 25, diciembre 1999-marzo de 2000: 22-23) y «Las notas que se aman» (núm. 30, noviembre de 2001: 12-14).

Una de las obras de Martín López-Vega (Poo de Llanes, 1975), titulada Cartas portuguesas (López-Vega, 1997), tiene un claro contenido autobiográfico. Su publicación primigenia tuvo lugar en el suplemento «La Mirada» de El Correo de Andalucía, entre noviembre de 1996 y junio de 1997. El autor escribió además fragmentos de su diario para Reloj de arena: «Algunos días, ciertas noches» (núm. 11, marzo de 1994: 23-26) y «Cuaderno de Venecia» (núm. 35-36, verano de 2003: 44-54) ${ }^{21}$.

Por lo que respecta al teatro (Romera Castillo, ed., 2003), el dramaturgo Fernando Arrabal (Melilla, 1932), que ha dejado huellas autobiográficas en sus artículos del diario El Mundo, desde 1994, es autor de un diario titulado Sueños pánicos de unas noches de verano, cuyos fragmentos fueron apareciendo por entregas en Diario 16, a lo largo del mes de agosto de 1988, todos los días excepto los domingos. Dichos textos, en los que están presentes los elementos ficticios, se recopilaron en un libro más de treinta años después (Arrabal, 2011), en una edición revisada y corregida por el propio Arrabal.

En otros ámbitos, destacaré algunas entregas. El psiquiatra, neurólogo y escritor Carlos Castilla del Pino, cuyos libros de memorias son bien conocidos - Pretérito imperfecto. Autobiografía (1922-1949) (1997) у Casa del olivo. Autobiografía (1949-2003) (2004)—, publicó «Fragmentos de diario» en el Boletín de la Unidad de Estudios Biográficos (núm. 2, 1997: 99-100), unos meses después de obtener el Premio Comillas por Pretérito

20 A estos volúmenes hay que añadir Catálogo de asombros (Almuzara, 2012), que incluye tanto escritos ensayísticos como de crítica musical y autobiográficos.

21 También en dicha revista aparecieron los únicos textos diarísticos que han publicado hasta la fecha al menos otros cuatro poetas asturianos relevantes: Pelayo Fueyo (Gijón, 1967) — «Un pájaro en la luna (Diario, marzo-junio, 1993)», Reloj de arena 17, mayo de 1997: 14-15 y «Diario de una momia», ibid. 77, septiembre-octubre de 2008: 20-22—; José Luis Piquero (Mieres, 1967) («Bodas en casa», ibid. 12, junio de 1995: 26-29); Vicente García (Gijón, 1971) («Cuaderno de bitácora», ibid. 25, diciembre de 1999-marzo de 2000: 24 y 27) y Marcos Tramón (Oviedo, 1971) («Anotaciones», ibid. 10, diciembre de 1994: 22). Pelayo Fueyo es además autor de «un diario largo comprendido entre 1993 y 1996», que permanece inédito (Correspondencia con el autor, de 13 de septiembre de 2012). 
imperfecto. Se trata de sendas anotaciones correspondientes a los años 1948, 1957 y 1968.

Iñaki Uriarte, escritor y crítico literario vasco, nacido en Nueva York en 1946, ha publicado los libros Diarios. 1999-2003 (2010) - Premio «Euskadi» de Literatura 2011 en la modalidad de ensayo en castellano- y Diarios (segundo volumen, 2004-2007) (2011), galardonados ambos como conjunto con el XXXIII Premio «Tigre Juan». También firmó dos textos autobiográficos en la revista Clarín: «Diario de un hombre tranquilo (1999)» (núm. 72, noviembre-diciembre 2007: 16-26) y «El gato Borges. Entradas de un dietario, 2001-2008» (núm. 78, noviembre-diciembre de 2008: 21-27).

En 1996, el número de la Revista de Occidente ${ }^{22}$ al que ya se ha hecho referencia, dedicado al diario íntimo, incluyó textos diarísticos de diferentes autores españoles ${ }^{23}$ (con el nombre de cada uno de ellos como título): Felipe Benítez Reyes, quien ya había publicado notas del periodo 1981-1990 bajo el título La maleta del náugrago (1991); José Carlos Llop —el escritor mallorquín ya había firmado los dos primeros volúmenes de su diario, titulados La estación inmóvil (1990) y Champán y sapos (1994), y en 1996 veía la luz el tercero, Arsenal-; Antonio Martínez Sarrión, quien, en lo que se refiere a lo autobiográfico, ya había publicado entonces el primero de los tres tomos de sus memorias, Infancia y corrupciones (1993) y el primero de los tres volúmenes de su diario aparecidos hasta hoy, Cargar la suerte (1995); Carmen Riera, que dos años más tarde dio a la imprenta el diario de un embarazo, Temps d'una espera, con versión castellana (Tiempo de espera); Miguel Sánchez-Ostiz - las anotaciones de sus diarios y dietarios posteriores a 1995 se han publicado, desde 2001, en las entregas La casa del rojo (2001), Liquidación por derribo (2004), Sin tiempo que perder (2009), Vivir de buena gana (2011) e Idas y venidas (2012)_; el poeta gallego Antón Tovar, que en 2001 publicó su Diario íntimo dun vello revoltado y Andrés Trapiello, en cuyos diarios nos hemos detenido ya.

Los demás textos seleccionados en el número de la Revista de Occidente que nos ocupa pertenecen a los siguientes autores: Bernardo Atxaga (anotaciones de un viaje de ese mismo año a Finlandia, traducidas por el propio Atxaga del euskera al castellano); Laura Freixas, que con posterioridad también ha publicado textos diarísticos en otras revistas, como es el caso del «Diario de una novela» (Letras Libres 44, mayo 2005: 42-45), itinerario

22 Núm. 182 y 183, julio-agosto de 1996: 159-256.

23 Sobre la ausencia de José Luis García Martín en esta selección, vid. nota 17. 
creativo de su obra Amor o lo que sea (2005); Julia Escobar; José Jiménez Lozano; Juan Antonio Masoliver Ródenas; Justo Navarro y Juana Salabert.

\section{CONCLUSIONES}

En este breve - y selecto- estudio se ha tratado de configurar un panorama de la presencia que la literatura autobiográfica ha tenido en la prensa española a lo largo de las últimas décadas. Su auge se ha visto sin duda reflejado en las páginas de los diarios y de las revistas culturales y literarias, en las que la llamada «escritura del yo» ha estado muy presente. La mayor parte de los escritores de nuestro país que han publicado, desde 1975, autobiografías, memorias y diarios, han firmado también en la prensa parte de dichos textos, bien como adelantos o entregas de sus libros, como colaboraciones periodísticas recopiladas posteriormente en volúmenes, o como textos esporádicos e independientes.

A partir de dicha fecha la literatura autobiográfica ha contribuido en nuestro país a rescatar «una realidad oscurecida» (Caballé, 1995: 219), tras cerca de cuatro décadas de dictadura. Para dicha recuperación, y para el avance de lo autobiográfico hacia nuevas perspectivas, la prensa ha jugado un papel fundamental. También ha sido clave en el nacimiento y en la difusión de una parte considerable de los escritos, como sucedió con otros géneros literarios desde el siglo XVIII. Una vez más, se pone de manifiesto la importancia de la prensa como espacio creativo, al igual que su interés para el estudio de la literatura de una determinada época.

\section{REFERENCIAS BIBLIOGRÁFICAS}

ALBERCA, M. (2000). La escritura invisible. Testimonios sobre el diario íntimo. Madrid: Sendoa.

ALBERTI, R. (1987). La arboleda perdida. Libros III y IV de memorias. Barcelona: Seix Barral.

- (2009). Obras completas. Prosa II. Memorias. La arboleda perdida. Barcelona: Seix Barral.

ALMUZARA, J. (2001). Letra y música. Gijón: Llibros del Pexe.

- (2005). Títere con cabeza. Logroño: AMG Editor.

- (2012). Catálogo de asombros. Gijón: Impronta. 
ARRABAL, F. (2011). Sueños pánicos de unas noches de verano. Zaragoza: Libros del Innombrable.

AYALA, F. (2006). Recuerdos y olvidos. Madrid: Alianza Editorial.

- (2010). Obras completas II. Autobiografía(s). Barcelona: Galaxia Gutenberg-Círculo de Lectores.

BARRERO, H. (2003). Las estaciones del día. Gijón: Llibros del Pexe.

BASANTA, A. y LOUREIRO, Á. G. (1996). «La autobiografía desde 1975». Ínsula 589-590, 9-11.

CABALLÉ, A. (1991). «Memorias y autobiografías en España (siglos XIX y XX)». Anthropos, suplemento extraordinario 29, 143-169.

- (1995). Narcisos de tinta. Málaga: Megazul.

- (1996). «Ego tristis (El diario íntimo en España)». Revista de Occidente 182-183, julio-agosto, 99-120.

CELA, C. J. (1993). Memorias, entendimientos y voluntades. Madrid: Espasa.

- (2001). La rosa. Madrid: Espasa (1. ${ }^{\text {a }}$ ed. ${ }^{\circ}$ 1959).

CUENCA, L. A. de (1993). Etcétera. Sevilla: Renacimiento.

- (1995). Álbum de lecturas. Madrid: Huerga \& Fierro.

- (1999). Señales de humo. Valencia: Pre-Textos.

- (2011a). Libros contra el aburrimiento. Madrid: Reino de Cordelia.

- (2011b). Nombres propios. Valladolid: Universidad de Valladolid.

CHACEL, R. (1972). Desde el amanecer. Madrid: Revista de Occidente.

- (1993a). Obra completa. Artículos I. Valladolid: Diputación Provincial / Centro de Estudios Literarios / Fundación Jorge Guillén.

- (1993b). Obra completa. Artículos III. Valladolid: Diputación Provincial / Centro de Estudios Literarios / Fundación Jorge Guillén.

DELIBES, M. (2007). Obras completas VII. Barcelona: Destino.

FERNÁNDEZ PRIETO, C. y HERMOSILLA ÁLVAREZ, M. á. (eds.) (2004). Autobiografía en España: un balance. Madrid: Visor Libros.

FERNÁNDEZ, J. (1991). «Textos autobiográficos españoles de los siglos XVIII, XIX y XX. Bibliografía». Anthropos 125, 20-23.

FREIXAS, L. (1996). «Auge del diario iíntimo? en España». Revista de Occidente 182-183, julio-agosto, 5-14.

GALA, A. (1988). Dedicado a Tobías. Barcelona: Planeta.

GARCÍA MARTÍN, J. L. (1995). Dicho y hecho. Sevilla: Renacimiento.

- (1997). Todo al día. Gijón. Llibros del Pexe. 
GARCÍA MARTÍN, J. L. (2006). A decir verdad. Gijón: Llibros del Pexe.

- (2007). La vida misma. Mieres: Universos.

- (2009). Hotel Universo. Oviedo: Trabe.

- (2011). Para entregar en mano. Sevilla: Isla de Siltolá.

GARCÍA MONTERO, L. (1992). Luna en el sur. Sevilla: Renacimiento.

- (2003). La casa del jacobino. Madrid: Hiperión.

GIL DE BIEDMA, J. (1991). Retrato del artista en 1956. Barcelona: Lumen.

GONZÁLEZ, Á. (1990). «Autopercepción intelectual de un proceso histórico». Anthropos 109, 19-29.

- (1998). 50 años de periodismo a ratos y otras prosas. Oviedo: Ediciones Nobel.

GOÑI, J. (1993). «El paso del tiempo. Los escritores españoles ven los diarios como un género y no como una confesión personal». El País, suplemento «Babelia» 97, 21 de agosto, 10-11.

GOYTISOLO, J. (1993). Cuaderno de Sarajevo. Madrid: El País-Aguilar.

GRACIA, J. (1993). «La autobiografía como invención y literatura. Bryce Echenique, C. J. Cela y M. Vargas Llosa». El Ciervo 506, 25-28.

- (1997). «El paisaje interior. Ensayo sobre el dietarismo español contemporáneo». Boletín de la Unidad de Estudios Biográficos 2, enero, 39-50.

GRACIA, J. et alii (2000). Los nuevos nombres. 1975-2000. Barcelona: Crítica (vol. 9, primer suplemento, de Historia y crítica de la literatura española, dirigida por Francisco Rico).

GRACIA, J. y MAINER, J.-C. (2000). «El diario de escritor». En Los nuevos nombres. 1975-2000, Jordi Gracia et alii, 448-460. Barcelona: Crítica (vol. 9, primer suplemento, de Historia y crítica de la literatura española, dirigida por Francisco Rico).

JUARISTI, J. (2006). Cambio de destino. Barcelona: Seix Barral.

LEJEUNE, Ph. (1971). L'autobiographie en France. París: A. Colin.

- (1975). Le pacte autobiographique. París: Seuil.

- (1986). Moi aussi. París: Seuil.

- (1994). El pacto autobiográfico y otros estudios. Málaga: MegazulEdymión.

LÓPEZ-VEGA, M. (1997). Cartas portuguesas. Gijón: Llibros del Pexe. 
LOUREIRO, Á. G. (1991). «La autobiografía española: actualidad y futuro». Anthropos 125, 17-20.

MARÍAS, J. (2008). Aquella mitad de mi tiempo. Barcelona: Círculo de Lectores / Galaxia Gutenberg.

MOLINA, C. A. (1992). «La obra periodística de Torrente Ballester». En Torre del aire, Gonzalo Torrente Ballester, I-XXI. Edición y prólogo de César Antonio Molina. La Coruña: Diputación Provincial.

MUÑOZ MOLINA, A. (1989). Diario de Nautilus. Madrid: Mondadori. 1. ${ }^{\mathrm{a}}$ ed. 1986.

- (1995). Las apariencias. Madrid: Alfaguara.

- (1996). La huerta del Edén. Madrid: Ollero \& Ramos.

NÚÑEZ DÍAZ, P. (2011). Las colaboraciones de Javier Marías en la prensa. Opinión y creación. Madrid: Universidad Nacional de Educación a Distancia.

PANERO, J. L. (1994). Los mitos y las máscaras. Barcelona: Tusquets.

PUÉRTOLAS, S. (1996). Recuerdos de otra persona. Barcelona: Anagrama.

ROMERA CASTILLO, J. (1991). «Panorama de la literatura autobiográfica en España (1975-1991)». Anthropos, suplemento extraordinario 29, diciembre, 170-184.

- (1993). «Hacia un repertorio bibliográfico (selecto) de la escritura autobiográfica en España (1975-1992)». En Escritura autobiográfica, José Romera Castillo et alii (eds.), 423-505. Madrid: Visor Libros.

- (1996). Con Antonio Gala (Estudios sobre su obra). Madrid: Universidad Nacional de Educación a Distancia.

- (2000). «Se hace camino al vivir. Diarios de algunos poetas españoles actuales (1975-1993)». En Poesía histórica y (auto)biográfica (19751999), José Romera Castillo y Francisco Gutiérrez Carbajo (eds.), 105118. Madrid: Visor Libros.

- (2004). «Algo más sobre el estudio de la escritura diarística en España». En Autobiografía en España: un balance, Celia Fernández Prieto y María Ángeles Hermosilla Álvarez (eds.), 95-112. Madrid: Visor Libros.

- (2006a). De primera mano. Sobre escritura autobiográfica en España (siglo XX). Madrid: Visor Libros.

- (2006b). «Diarios literarios españoles (1993-1995)». En De primera mano. Sobre escritura autobiográfica en España (siglo XX), José Romera Castillo, 367-379. Madrid: Visor Libros. 
ROMERA CASTILLO, J.(2006c). «Escritura autobiográfica cotidiana. El diario en la literatura española actual (1975-1991)». En De primera mano. Sobre escritura autobiográfica en España (siglo XX), José Romera Castillo, 341-366. Madrid: Visor Libros.

- (2006d). «Escritura autobiográfica de Miguel Delibes». En De primera mano. Sobre escritura autobiográfica en España (siglo XX), José Romera Castillo, 279-290. Madrid: Visor Libros.

- (2010a). «La escritura (auto)biográfica y el SELITEN@T». Signa 19, 333-369 (también puede leerse en http://descargas.cervantesvirtual. com/servlet/SirveObras/12476280980181621332679/035521. pdf? incr $=1$ ).

- (2010b). «Algo más sobre la escritura autobiográfica de Miguel Delibes». En Cruzando fronteras: Miguel Delibes entre lo local y lo universal, M. ${ }^{a}$ Pilar Celma Valero y José Ramón González (eds.), 113-131. Valladolid: Cátedra Miguel Delibes.

ROMERA CASTILLO, J. (ed.) (2003). Teatro y memoria en la segunda mitad del siglo XX. Madrid: Visor Libros.

ROMERA CASTILLO, J. et alii (eds.) (1993). Escritura autobiográfica. Madrid: Visor Libros.

ROMERA CASTILLO, J. y GUTIÉRREZ CARBAJO, F. (eds.) (2000). Poesía histórica y (auto)biográfica (1975-1999). Madrid: Visor Libros.

SÁNCHEZ ROBAYNA, A. (1996). La inminencia (Diarios, 1980-1995). Madrid: Fondo de Cultura Económica.

- (2002). Días y mitos (Diarios, 1996-2000). Madrid: Fondo de Cultura Económica.

SEMPRÚN, J. (1998). Adiós, luz de veranos. Barcelona: Tusquets.

TORRENTE BALLESTER, G. (1976). Nuevos Cuadernos de La Romana. Barcelona: Destino.

- (1987). Cotufas en el golfo. Barcelona: Destino. 1. ${ }^{\text {a }}$ ed. ${ }^{\circ} 1986$.

- (1992). Torre del aire. La Coruña: Diputación Provincial. Edición y prólogo de César Antonio Molina.

TRAMÓN, M. (2005). Años, libros, vida. Bibliografía comentada de José Luis García Martín. Gijón: Llibros del Pexe.

TRAPIELLO, A. (1990). El gato encerrado. Valencia: Pre-Textos.

- (1993). Locuras sin fundamento. Valencia: Pre-Textos.

- (1998). El escritor de diarios. Barcelona: Península. 
TRAPIELLO, A. (2000). Do fuir. Valencia: Pre-Textos.

UMBRAL, F. (1976). Iba yo a comprar el pan. Madrid: Ediciones Sedmay.

- (1978). Diario de un snob /2. Barcelona: Bruguera.

- (1979). Diario de un escritor burgués. Barcelona: Destino.

- (1994). Mis placeres y mis días. Madrid: Espasa Calpe.

VILA-MATAS, E. (2008). Dietario voluble. Barcelona: Anagrama.

VILLENA, L. A. de (1982). Ante el espejo. Barcelona: Argos Vergara.

VV. AA. (2000). «Prosa autobiográfica y literatura». En Los nuevos nombres. 1975-2000, Jordi Gracia et alii, 425-448. Barcelona: Crítica (vol. 9, primer suplemento, de Historia y crítica de la literatura española, dirigida por Francisco Rico).

- (2002). Literatura y memoria. Jerez de la Frontera: Fundación Caballero Bonald.

Recibido el 11 de mayo de 2013.

Aceptado el 19 de septiembre de 2013. 